Journal of English Language Teaching and Applied Linguistics

ISSN: 2707-756X

DOI: $10.32996 /$ jeltal

Journal Homepage: www.al-kindipublisher.com/index.php/jeltal

JELTAL

\title{
Mapping Out the Future: A Proposal of A CLIL Research Agenda in China
}

\author{
Hengzhi Hu 8 (D) \\ Faculty of Education, The National University of Malaysia (UKM), Bangi, Malaysia
}

$\triangle$ Corresponding Author: Hengzhi Hu, E-mail: p108937@siswa.ukm.edu.my

\begin{abstract}
ARTICLE INFORMATION ABSTRACT
Received: July 08, 2021

Accepted: August 10, 2021

Volume: 3

Issue: 9

DOI: 10.32996/jeltal.2021.3.9.1

\section{KEYWORDS}

CLIL, research, evidence-based

practice, Chinese academia

This paper sets out to place the research on Content and Language Integrated Learning (CLIL) within the border of Chinese academia. In considering the limited amount of empirical research in China, the author problematises the construction of a shared CLIL research agenda aimed at extending the scope of the current academic scenario. A conceptual model is formulated based on the constructive proposal brought forward by Coyle et al. (2010) that CLIL research should involve the examination and understanding of performance evidence, affective evidence, process evidence and materials and task evidence. Given that almost all the reviewed CLIL studies were conducted in the scope of English language education in higher education, this model is positioned within a broad multilingual and educationally diverse context in China. A more comprehensive, rich and evidence-based research scenario is expected from Chinese researchers whose work is not only to extend the CLIL research agenda but also to probe into it in the long way ahead.
\end{abstract}

\section{Introduction}

The concept of teaching subject knowledge via a foreign language can be dated back to 5,000 years ago when the Akkadian conquerors started to learn Sumerian languages in order to settle into the local society (Mehisto et al., 2008), while it was until the 1990s that the notion of Content and Language Integrated Learning (CLIL) was proposed in Europe by David Marsh under the influence of the European Union's multilingual contexts and language policies as well as the success of bilingual education programmes in other multilingual countries (Hanesová, 2015). Although "CLIL cannot be fairly said to be ground-breaking in the second language instruction landscape" with its analogous approaches having been unostentatiously adopted much earlier (Alba, 2009, p. 131), it is still one of the most attention-catching pedagogical approaches which has kindled considerable and increasing research interest in the field of either foreign language education or subject education, the momentum of which is "unlikely to be reversed in the foreseeable future" (Dearden \& Macaro, 2016, p. 465) like "an unstoppable train which has already left the station" (Macaro, 2019, p. 232).

With the massive upsurge of CLIL research especially in the western world, Pérez Cañado (2018) has identified four key evolving moments in the CLIL arena, namely craze, critique, conundrum and controversy. In her latest publication, she maintains that the initial stage of CLIL craze wherein the bloom of research studies, though a majority of which are assumed to be problematic in research designs, has heaped praise on the functioning of CLIL and generally ended and transitioned to the next one of critique in which a pessimistic view is held toward CLIL based on unsubstantial assumptions and personal experience characterised by a lack of academic rigour and robustness (Pérez Cañado, 2020). The conflict between craze and critique has further resulted in a CLIL conundrum "where confusion, as regards the effectiveness of CLIL, has predominated" as well as a CLIL controversy, a position of the current research scope between CLIL advocates and detractors which necessitates the re-examination of the pivotal aspects of CLIL and previous research studies (Pérez Cañado, 2020, p. 1). However, this may not be the exact case in China, as Pérez Cañado's (2020) proposal of a CLIL research agenda along with many of the others formulated based on a vast amount of empirical evidence (Coyle, 2007; Dalton-Puffer \& Smit, 2013; Llinares, 2015) has excluded Chinese academia from the scope. Although the introduction of CLIL into Asian countries (Tsagkari, 2019) as well as China (Luo, 2006) has already started in the early twenty-first century, this pedagogical approach is still a relatively new issue to be explored given that it is a seldom

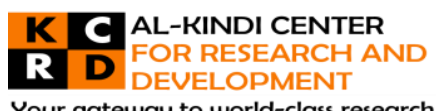

Your gateway to world-class research

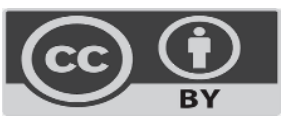

Published by Al-Kindi Center for Research and Development, United Kingdom. Copyright (c) the author(s). This open access article is distributed under a Creative Commons Attribution (CC-BY) 4.0 license 
known "brand name" that enjoys limited publicity "for its association with language pedagogical innovation and effectiveness" (Xiong, 2018, p. 178).

Bearing this brief introduction in mind, I wish to focus on the background of China and examine what is hot and what is not in recent CLIL academia by reviewing and referring to updated and classic literature, based on which a context-specific research model is proposed aimed at extending the scope of CLIL studies in China with a small but constructive effort.

\section{What do we mean by CLIL?}

Marsh (2002, p. 15) defines CLIL as "an umbrella term which refers to a dual-focused educational context in which an additional language, thus not usually the first foreign language of the learners involved, is used as a medium in the teaching and learning of non-language content". This definition is similar to the one put forward by Coyle et al. $(2010$, p. 1) that CLIL is "a dual-focused educational approach in which an additional language is used for the learning and teaching of both content and language" and that "in the teaching and learning process there is a focus not only on content and not only on language". To simply put, CLIL is essentially innovative in the manner that both language and content are the learning focuses and that students learn the language via the conduit of content and learn the content in the medium of the target language (TL). This relationship is illustrated in Figure 1 which displays that the purpose of learning a foreign language is to learn the discipline content and that the learning of content allows learners to learn and use the TL. Such a simultaneous teaching and learning process creates a natural environment in which the dual aims of language learning and content learning can be realised (Marsh, 2002).

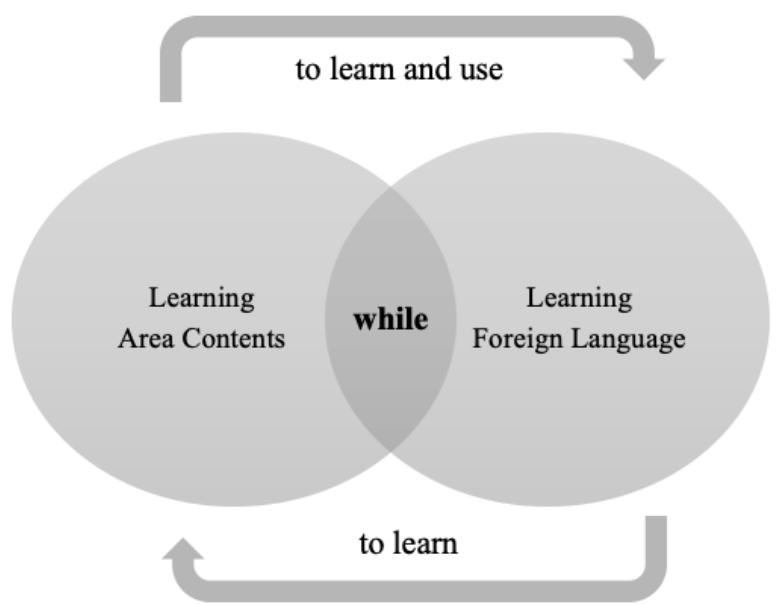

Figure 1: Relationship between Language and Content in CLIL

What has made CLIL so attractive to educators and researchers is probably its 4Cs-Framework formulated by Coyle (1999; 2007), which summarises the key features of this pedagogical approach from the perspectives of content, communication, cognition and culture as four major building blocks. This can be seen in Figure 2. Specifically, according to Thamrin and Kuntariati (2015, pp. 313-314), content "provides learning contexts which are relevant to" learners' needs and interests and "supports the integration of language into the broader curriculum"; communication "involves using language in the here and now to construct new knowledge and skills" and "offers direct opportunities to learn through language and to make meanings that matter"; cognition "promotes learner progression in both language...and knowledge construction" and reinforces the interconnection "between language development and thinking skills"; culture creates a link between "language and cultural identity" and "involves contexts and content which enrich the learners' understanding" of diverse language and cultural experiences. This, as a pedagogical framework, recognises the complicated but essential interrelationship between language learning and content learning with a set of theoretically rich principles embedded behind it. 


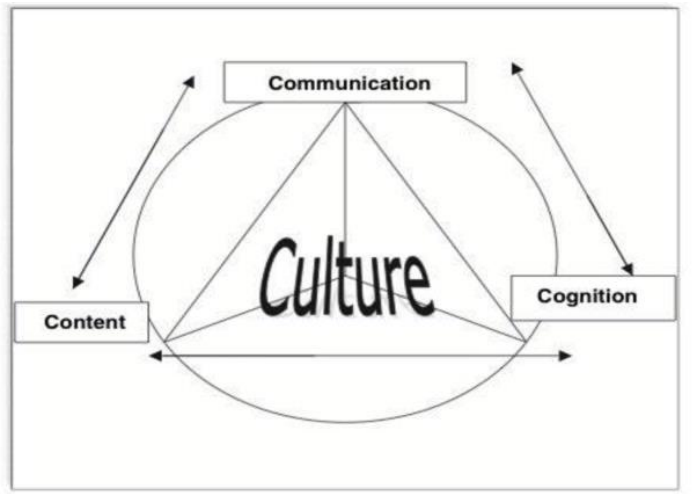

Figure 2: 4Cs-Framework of CLIL (Coyle, 2007, p. 551)

As mentioned previously, the notion of CLIL is not new. Instead, it has been already practiced thousands of years ago in foreign language education. Nowadays, there are numerous CLIL-like methods that tend to be named differently, and McDougald (2012, as cited in Samper, 2015) has identified over forty types of practices that are more or less similar to CLIL, such as Content-based Instruction (CBI), Topic-based Language Teaching, Content-centred English Teaching, Content-based Language Teaching (CBLT), Integrated Curriculum, Teaching Through Foreign Language (TTFL), English-Medium Instruction (EMI), etc. However, a hot debate is always on the comparison of CLIL, CBI and EMI. The border between EMI with the other two approaches has been now very clear, as EMI focuses on the complete use of English as the medium of instruction in order to facilitate the acquisition of content area knowledge for those learners whose first language is not English (Unterberger \& Wilhelmer, 2011). However, the border between CLIL and CBI is not always explicit, with some scholars arguing that CLIL and CBI are the two sides of the same coin and do not differ from each other (Cenoz, 2015) and some others maintaining that these two approaches are basically different with CBI focusing on content learning and CLIL stressing both content and language learning (Brown \& Bradford, 2017). Probably this debate derives from the definition of $\mathrm{CBI}$ which is "an umbrella term that refers to instructional approaches that make a dual, though not necessarily equal, commitment to language and content-learning objectives" (Stoller, 2008, p. 59). This makes it pretty much the same as CLIL. Indeed, these two approaches share many common features, such as using the TL to acquire content knowledge, paying special attention to language learning and cognitive development, emphasising the nature of input hypothesis and constructivism, to name but a few (Yang, 2016). However, my personal view, in line with many other scholars' (e.g. Baker \& Wright, 2017; Brown \& Bradford, 2017; Yang, 2016), is that CLIL differs from CBI in the manner that: first, they were initially introduced in very differing socio-educational contexts, because of which the application could be very different; second, CBI which was firstly introduced and applied widely in America is embedded in a monolingual and assimilationist mindset, which is opposite to CLIL as a form of bilingual education aimed at helping students to attain proficiency in an additional language. Of course, the context is important, and how educators utilise CBI or CLIL in their classroom practice really matters here if a clear distinction has to be drawn between them. However, my personal opinion that they are two different approaches is anchored in this paper, and it will be reviewed again in what follows.

\section{The Present CLIL Research Agenda in China: An Unbalanced Scenario}

The new century has witnessed the upsurge of interest in CLIL in China's academia, with an increasing number of researchers and educators attempting to explore the potential of this pedagogical approach in domestic educational contexts. However, a majority of studies still appear to remain at a theoretical level and focus on discussing the theories, pros and cons of CLIL with only a little empirical research exploring the application of CLIL in real classroom contexts.

To explore the recent CLIL research agenda in China, Yang and He (2019), using CLIL and its Chinese counterparts as keywords, selected 110 academic articles indexed in China National Knowledge Infrastructure (CNKI) ${ }^{2}$ from 2010 to 2019 and firstly classified them under theoretical exploration, curriculum cases, teacher development and research review. The authors provided an extensive description of these four categories and maintained that the publications characterised by theoretical exploration of CLIL and its implications for either English language teaching or content teaching across a wide range of education levels and disciplines occupied $80 \%$ of the total publications. In combination with further research finding that $94.6 \%$ of the chosen publications were non-empirical $(N=104)$ with only 6 empirical research reports, Yang and He (2019) concluded that despite the effort that had been made to introduce and discuss the theories related to CLIL, empirical studies should be emphasised more in days to come in order to expand the scope of CLIL research in China.

2 China National Knowledge Infrastructure (CNKI) is the most authoritative, comprehensive and largest research and information publishing institution in China led by Tsinghua University and Chinese government apparatuses. 
Liu (2019), using CiteSpace network analysis and CLIL and CBI as keywords, chose and analysed more than 800 publications indexed in CNKI from 2008 to 2017 and stated that most of them showed a high level of theoretical engagement instead of offering much empirical evidence on the application of these educational approaches. The researcher also concluded that the potential of CLIL in English language education (ELE) had received a great deal of emphasis in academic discourses, leaving a gap in the education of other foreign languages. Similarly, in Mi's (2015) study wherein he used both CLIL and CBI as keywords for article selection, over 40 articles published in core journals of China from 2004 to 2013 were analysed and categorised into theoretical exploration (26.83\%), subject curriculum construction (17.07\%), implementation effects (36.59\%), feasibility and applicable conditions (7.32\%), classroom-based research (0\%), teacher development (2.44\%), teaching materials design (2.44\%), summaries of conferences (4.88\%) and book reviews (2.44\%). Unfortunately, Mi (2015) did not provide any detailed information on these category labels, some of which might appear vague. Nevertheless, it can be noted that empirical studies featured by classroom-based research and implementation effects only occupied a small proportion of the total publications selected, based on which the researcher concluded that a limited amount of empirical research on CLIL had been done in China. Likewise, Wang and Xing's (2021) latest research, in which they selected 962 publications indexed in CNKI from 2002 to 2020 based on the keywords of CLIL and CBI, showed that only $36.2 \%$ of the publications were characterised by evidence-based empirical studies, far lower than those typified by theoretical exploration and review. This has also led to the same conclusion that the academic discourse of CLIL has been long on claims but short on empirical research.

However, it should be noted that Mi (2015), Liu (2019), Wang and Xing (2021) used CLIL and CBI as keywords for article selection, the equalisation of which has been previously rejected by both Chinese and foreign scholars who believe that CBI and CLIL initially proposed in highly different educational and social settings are not necessarily the same thing that has the identical pedagogical principles and implications (Dalton-Puffer \& Smit, 2013; Brown \& Bradford, 2017; Yang, 2016; Yu \& Xiang, 2018). It is also further dispelled by Chang and Zhao (2020) who, based on their extensive review of CBI and CLIL research studies in Chinese educational contexts, argue that the application of $\mathrm{CBI}$ in practice has not really displayed the nature of contentlanguage integration compared with CLIL in the manner that a wide variety of subject areas have only been used to theme foreign language teaching and learning, the probably one and only objective of CBI-based classes. In this sense, although these researchers have come up with the same findings as Yang and He (2019) have, the former's works could not provide a precise enough overview of the CLIL research agenda in China.

To provide the latest and a more accurate overall review of the CLIL research scenario, the author of this paper used CLIL and its Chinese counterparts as keywords, selected and examined 114 publications indexed in CNKI from 2012 to July 2021 . First of all, as shown in Figure 3, there was a general increase in the number of CLIL-related publications in China. After 2017, the upward trend has become particularly manifest. Although there were only 8 publications found upon the construction of this paper, it is expected that the interest in CLIL would not fade, given the upsurge of publications in the past few years. This is also acknowledged by Wang and Xing (2021), who believe that there is still large room to be explored about the application of and research on CLIL in China.

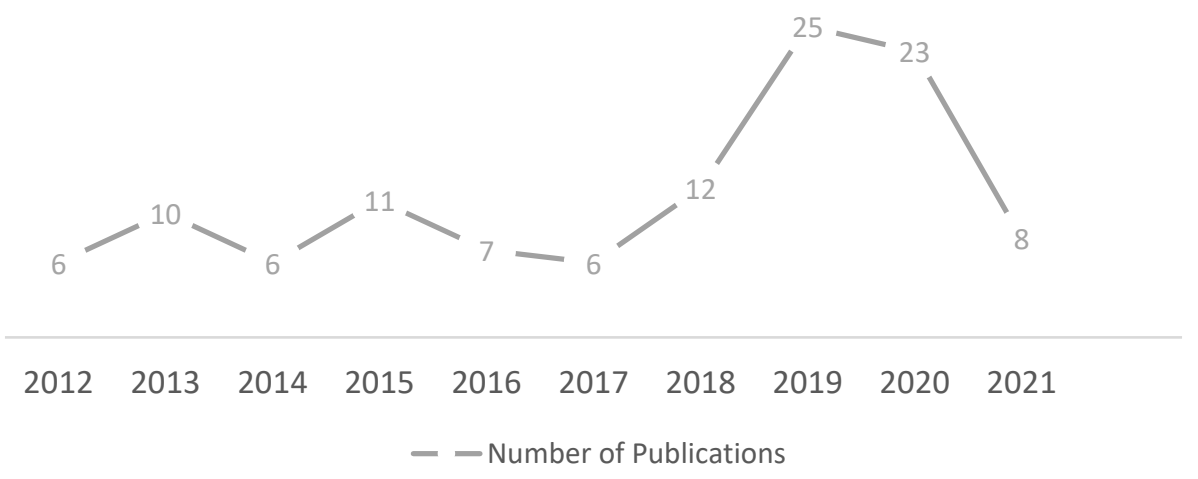

Figure 3: Number of CLIL-related Publications Indexed in CNKI from 2012 to 2021

Then, the selected publications were carefully reviewed and generally categorised into two groups, non-empirical theory-based papers and empirical evidence-based papers. As shown in Table 1, 82.5\% of the chosen publications were non-empirical and characterised by a theoretical endeavour to explore CLIL from various aspects, while only $17.5 \%$ were empirical and evidencebased aimed at exploring the application of CLIL in classroom settings. This finding is basically in line with the one generated by Yang and He (2019) that evidence-based CLIL publications still remains limited to a small part of the academia, though the 
statistics on empirical publications are much larger than those mentioned by Yang and He (2019). This is probably because they excluded CLIL-related theses from consideration.

\begin{tabular}{|c|c|c|}
\hline Category & Number of Publications & Percentage \\
\hline Non-empirical & 94 & $82.5 \%$ \\
\hline Empirical & 20 & $17.5 \%$ \\
\hline
\end{tabular}

Table 1: General Information of the Indexed Publications

Then, the evidence-based publications related to empirical CLIL studies were reviewed and categorised, the details of which can be seen in Table 2. Firstly, many of the selected publications were journal articles $(N=10)$ with the remaining ones being master's thesis $(N=8)$ and conference papers $(N=2)$. Most of them were characterised by mixed-methods designs $(N=16)$ employing both quantitative and qualitative research methods, and there were only a few studies that opted for either quantitative $(N=2)$ or qualitative $(N=2)$ designs. Regarding the area of focus, it is interesting to note that a number of studies focused on examining learners' perceptions, attitudes and/or motivation under CLIL instructions $(N=16)$ and that the understanding of CLIL process involving the design of curriculum and tasks $(N=14)$ and the exploration of the effects of CLIL on English proficiency $(N=10)$ was also the main research interest. Some other research areas were also detected, such as learning materials $(N=4)$, content learning proficiency $(N=1)$, cognitive thinking ability $(N=1)$ and learning strategies $(N=1)$, though the number of studies was very small. Most of these studies were set into the ELE contexts, such as English majors $(N=9)$, College English Teaching $(N=8)$, secondary school English teaching $(N=1)$ and English for Academic Purpose $(N=1)$, among which the application of CLIL into higher education tended to be the dominant stream of research. However, research on the teaching of foreign languages other than English was rather rare, with only 1 study focusing on Teaching Chinese to Speakers of Other Languages.

\begin{tabular}{|c|c|c|}
\hline Category & Details & Number \\
\hline Publication Type & Journal Article & 10 \\
\cline { 2 - 3 } & Master's Thesis & 8 \\
\cline { 2 - 3 } & Conference Paper & 2 \\
\hline Research Designs & Mixed-Methods Study & 16 \\
\cline { 2 - 3 } & Quantitative & 2 \\
\cline { 2 - 3 } & Qualitative & 2 \\
\hline Area of Focus & Learners' Perceptions, Attitudes and/or Motivation & 16 \\
\cline { 2 - 3 } & Learning Process (e.g., curriculum design, learning tasks) & 14 \\
\cline { 2 - 3 } & English Performance & 10 \\
\cline { 2 - 3 } & Learning Materials & 4 \\
\cline { 2 - 3 } & Content Learning Performance & 1 \\
\cline { 2 - 3 } & Cognitive Thinking Ability & 1 \\
\cline { 2 - 3 } & Learning Strategies & 1 \\
\hline Scope & English Majors & 9 \\
\cline { 2 - 3 } & College English Teaching (CET) ${ }^{3}$ Context & 1 \\
\cline { 2 - 3 } & Teaching Chinese to Speakers of Other Languages (TCSOL) in higher education & 1 \\
\cline { 2 - 3 } & Secondary School English Teaching & 1 \\
\cline { 2 - 3 } & English for Academic Purpose (EAP) in doctoral programmes & \\
\cline { 2 - 3 }
\end{tabular}

Table 2: Essential Features of Evidence-based CLIL Studies in China

Generally speaking, Chinese researchers have attempted to explore and understand the effects of CLIL from various perspectives. This can be particularly seen from the large amount of mixed-methods research "for achieving a holistic view of the phenomenon studied...by integrating findings from quantitative and qualitative investigation" (Hafsa, 2019, p. 47). This attempt has ensured that a relatively complete picture of CLIL application has been drawn at least based on the researchers' original designs, which is quite inspiring. However, the review of research areas has shown an unbalanced scenario in which the evidence related to learners' perceptions and emotions, learning contexts and language learning proficiency has been mostly emphasised,

\footnotetext{
${ }^{3}$ College English is a compulsory language unit available to the students whose majors are not related to English language studies in Chinese higher education providers.
} 
with other types of evidence which are of the same importance in shaping and facilitating the understanding of CLIL in China underemphasised. With respect to the research scope, it is easy to find that ELE has almost been the one and only context examined by most CLIL researchers. It is not hard to accept this fact, because English as a lingua franca is the most important foreign language in China, the proficiency in which is regarded by the society as a valuable asset to achieve globalisation and internationalisation (Liu \& Wu, 2015). However, it is somewhat astonishing to find that almost all the studies were done in Chinese higher education providers with other levels of education excluded from the research scope. The loss of balance between what is hot and what is less hot has presented a partial picture of the application of CLIL in China, leaving much space to be explored further. This reflects what Zhao et al. (2020) have maintained that there are still many questions to be answered with respect to CLIL in Chinese educational contexts and that instead of following western scholars' steps, a local agenda has to be figured out.

\section{The Future: A Comprehensive, Evidence-Based Picture of CLIL in Practice}

In recent years, a number of researchers have proposed elaborate ideas about how CLIL research should be designed to focus on different areas of interest. For instance, based on a thorough review of empirical studies, Pérez Cañado's (2020, p. 1) suggests that some CLIL research areas have lost or should lose their popularity in current academia, dismantling the assumptions with respect to egalitarianism, effects of CLIL and the contradiction between form-focused instructions with meaning-based ones which are put forward by Bruton (2019) - "and mapping out future pathways for progression which affect attention to diversity in bilingual education, incorporating a pluriliteracies approach, and replicating, extending and meta-analyzing existing research". However, Pérez Cañado's (2020) proposal was constructed based on the review of the studies mostly conducted in European contexts that are rather different from Chinese ones. In this sense, it may be too early to say that this research agenda is strong enough to be backed up in the Chinese research context, as indeed the application and research of CLIL in China now remains at the level of theoretical exploration, leaving a huge space to be explored for us in order to further understand the potential of this pedagogical approach.

In Pérez Cañado's (2011, p. 330) earlier publication, she argues that "a comprehensive and empirically valid picture of where CLIL schemes stand in" Europe should be painted under the circumstance that insufficient solid empirical evidence was available at the time to base conclusive claims about the benefits of CLIL and multilingual education. She also proposes, in line with Mehisto and Asser (2007), that the crucial questions recurrent in CLIL debates and controversies should be the focal points of further research, such as the effects of CLIL on the development of first language and foreign language, content learning proficiency, attitudinal and affective factors, differences between CLIL and non-CLIL learning settings, problems faced by key stakeholders involved in CLIL, to name but a few. To some degree, this proposal is similar to the one put forward later by Dalton-Puffer and Smit $(2013$, p. 545) who, from a different point of view, maintain that there are some underrepresented areas in literature related to CLIL studies, such as policy issues concerning "policy statements as well as stakeholders' perceptions of CLIL and its success", "classroom discourse as the prime site for the investigation of CLIL practices and their implications for the learning process" and classroom pedagogy "with the focus on potential differences between CLIL and non-CLIL settings". These proposals constructed in European contexts may appear outdated now due to the boom of interest in CLIL and pertinent studies in the past few years, and as mentioned previously, academia has witnessed the passing of CLIL craze and critique and the coming of CLIL conundrum and controversy (Pérez Cañado, 2020). Nevertheless, some of the points mentioned by these innovative scholars have considerable referential significance for the development of CLIL research agenda in China, just as the case pointed by Pérez Cañado (2011) and many of the others (Coyle et al., 2010) that a comprehensive and empirical picture should be drawn with an endeavour to present the academia with rich evidence on CLIL in practice.

Coyle et al. (2010) maintain that any empirical CLIL research should cover a wide range of evidence and assume that the limited CLIL pictures presented by researchers may lead to suspicion to the effectiveness of this educational pedagogy. Therefore, they propose that an ideal CLIL study should at least cover the presentation and interpretation of performance evidence on how students perform in CLIL, affective evidence related to learners' perceptions and emotions (e.g., motivation for learning and learning anxiety), process evidence along with materials and task evidence concerning how learning occurs in CLIL. However, academia tends to go against this proposal and has presented an unbalanced scenario of CLIL research, which to some extent may explain why current CLIL research agenda has moved into the era of controversy (Pérez Cañado, 2020). According to Muxí (2018), recent CLIL studies have paid a great deal of attention to the examination of performance evidence as the prime focus followed by the probe into affective evidence, while the amount of empirical research on learning process evidence and materials and task evidence has been very limited in comparison. This overall scenario can be seen in Figure 4 which displays the unbalanced relationship among the four aspects of evidence. 


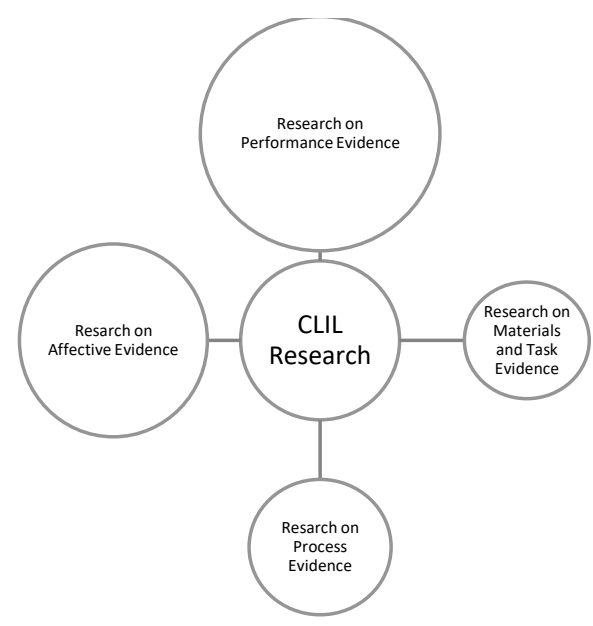

Figure 4. The Unbalanced Scenario of Recent CLIL Studies (Muxí, 2018)

However, Coyle et al.'s (2010) proposal which is further reinforced by the other researchers (Dalton-Puffer \& Smit, 2013; Pérez Cañado, 2011) is undoubtedly constructive. Although it may be a cliché in the contexts where a number of CLIL research studies have already been done since the introduction of it into language education, the idea of examining and understanding a wide range of evidence is valuable in the Chinese context given the late and hesitant start of empirical research and the incomprehensiveness of available evidence-based CLIL studies. Hence, from my own point of view, the research agenda suggested by Coyle et al. (2010) should be the direction in which Chinese CLIL researchers and scholars could follow at the current stage in order to present how the potential of CLIL is explored in China to the domestic and even global academia. In what follows, I would like to quote some of the details of the CLIL research agenda proposed by Coyle et al. (2010), as can be seen in Table 3, in order to provide Chinese researchers with a basic approach, though somewhat repetitive, into how future CLIL studies in China can move forward.

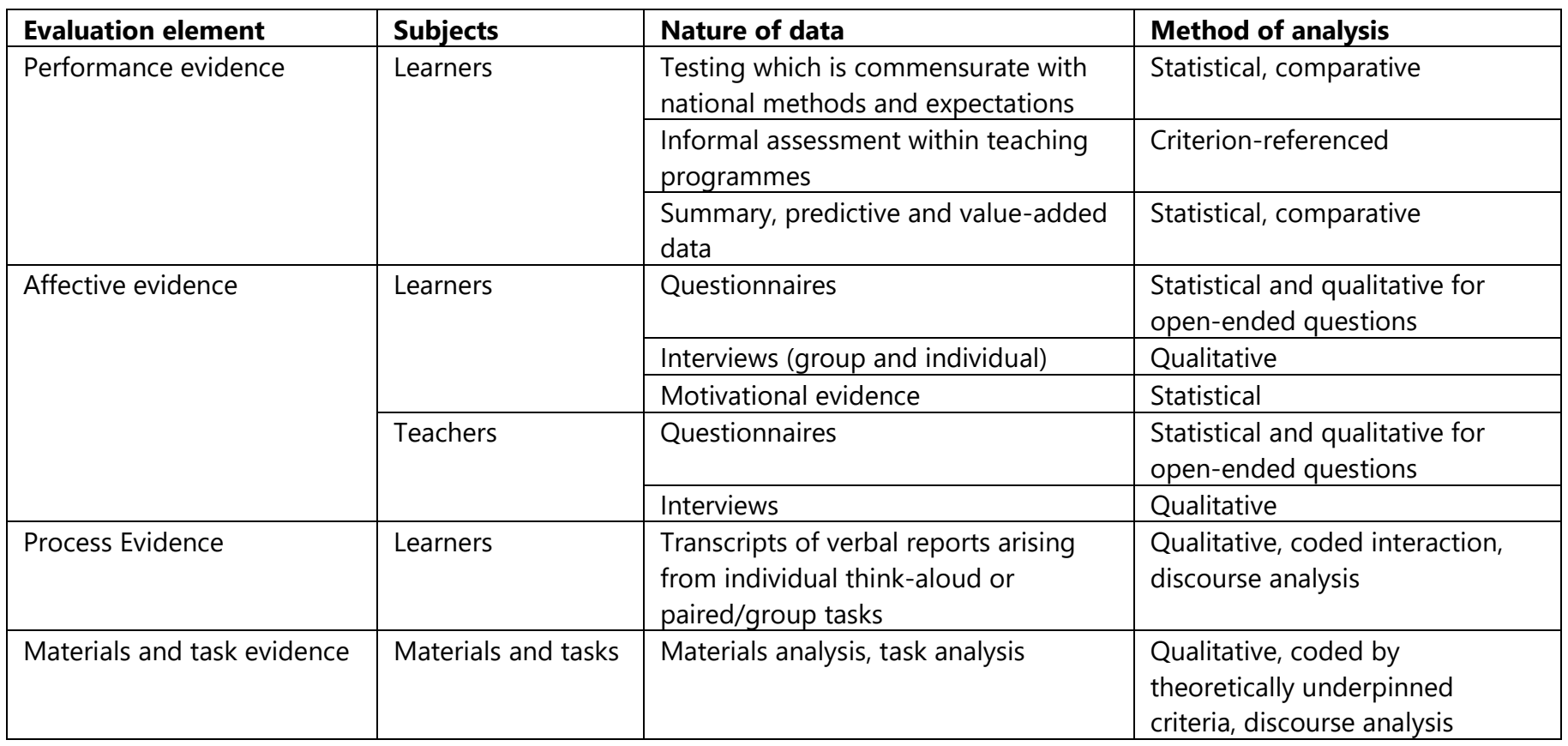

Table 3: A CLIL Research Agenda Adapted from Coyle et al. (2010, p. 211)

Probably, the best way to apply Coyle et al.'s (2010) proposal into practice is to adopt mixed-methods designs, combining both quantitative and qualitative research studies. This assumption is made due to the distinguished philosophies of quantitative and qualitative research, the combination of which can promote a better understanding of the phenomenon to be studied. With regard to performance evidence, quantitative designs involving the measure of students' language and content learning proficiency in a statistical way appear to be more appropriate, and such assessment includes but not limited to formative 
assessment that is "the frequent, interactive assessment of students' progress and understanding to identify learning needs" (Ahmed et al., 2019, p. 111) and summative assessment that "is the reflection of what they have learned in the past" (Ahmed et al., 2019, p. 110), though qualitative data on feedback gained from formative assessment are also a valuable source of evidence to examine the effectiveness of CLIL. Another straightforward way to study performance evidence is to adopt comparative research designs involving a treatment CLIL group and a control group. This lies in the idea that "comparing that item with other items can serve a heuristic purpose by identifying aspects and facets that would otherwise be missed or neglected" (Mari \& Shahrokh, 2019, p. 2). Coyle et al. (2010, p. 211) mention that the testing should be "commensurate with national methods and expectations". This view rightly fits in with the general examination-oriented educational contexts in China, and there are many well-established national standardised tests that researchers could use as instruments to collect data, though using standardised tests to assess CLIL can be also an issue of controversy because of potential assessment unreliability (Quartapelle, 2012).

The examination of affective evidence can be more flexible with either quantitative or qualitative designs or even both being appropriate, and common instruments include but not limited to questionnaires and interviews. I propose that documents, such as diaries, can be also used to record affective evidence based on my previous research experience that the participants used vivid drawings in their diaries to depict their emotions under CLIL instructions, though I did not add this point into the above table. The reasonability lies in the idea that documents are a valuable source of information on learners' perceptions and emotions which are changing continuously (Sheble \& Widlemuth, 2009). It is interesting to note that teachers can be also the main source of data when examining affective evidence. This is explained by Coyle et al. (2010, p. 219) that "teachers' knowledge of the affective side of their learners is vital in their own understanding of how to determine both the task styles and outcomes which will inspire learners and also the degree of scaffolding needed" to support and facilitate learning. The examination of process evidence is similar to that of materials and task evidence, and both of them involve qualitative designs, coded analysis, discourse analysis, etc. Therefore, classroom observation and documents are the major sources of data here, though at times open-ended questionnaires and interviews can be also used to achieve data triangulation.

Up to yet, how Chinese researchers can start with their empirical CLIL studies has been roughly reviewed. However, what Coyle et al. (2010) and many other scholars have missed out is that researchers should be encouraged to examine the multifaceted effects of CLIL in multilingual contexts which are normally taken for granted in Europe and many other western nations but should be definitely taken into consideration in the countries or regions where there is only one or two languages playing a dominant or official role with other languages, especially minority languages and heritage languages, having a less important role to play in education or society. Liu (2019) reveals that CLIL has been less studied in the education of languages other than English in China. This finding corresponds to what has been mentioned above that almost all the empirical CLIL studies have been set into the scope of ELE and excluded other languages from literature. China is a multilingual society in which English as a lingua franca has an undisputed role. However, since the introduction and establishment of reform and opening policies in the 1970s, the education of minority languages has also gained considerable popularity in various stages of education as a part of the national endeavour to achieve internationalisation at home (Deng, 2004; Huang et al., 2019; Liu, 2014). Meanwhile, heritage languages for ethnic minorities have also been attached to great importance by stakeholders aimed at carrying forward traditional culture and promoting multilingualism and multiliteracy (Zhou, 2013). In this sense, the scope of CLIL research should move beyond ELE and become more comprehensive in the manner that a multilingual context should be constructed in future CLIL studies.

Another aspect that is seldom taken into consideration by western researchers in their own contexts is that the effectiveness of CLIL should be examined amongst different age groups and at different levels of education. Of course, CLIL has been well studied in the western context, involving young learners in early childhood education (e.g., Iskos et al., 2017; Švecová, 2011), relatively older learners in primary and secondary schools (e.g., Chionis et al., 2017; Serra, 2007) and of course adult learners involved in higher education (e.g., Chostelidou \& Griva, 2014; Puerto \& Vázquez, 2016) and vocational education (Kováčiková, 2020; Sánchez-Palacios, 2017). Nevertheless, given the above discussion that CLIL in China has been mostly examined in higher education contexts with only one study conducted in the scope of secondary education, a more educationally diverse research scenario should be built, with experts from different levels of education involved to fully explore the potential of CLIL. It is indeed likely that any educational research involving the application and examination of innovative teaching pedagogies would encounter a great deal of resistance due to the highly examination-oriented educational context in China (Luo, 2021), whereas the latest educational policies have offered a great deal of top-down support for the reform and innovation of teaching and experiment with non-conventional teaching pedagogies. This can be seen from, for example, Guidelines for College English Teaching (College Foreign Language Teaching Steering Committee of the Ministry of Education, 2020) and English Teaching Reform in Primary School (Ministry of Education of the People's Republic of China, 2019) which illustrate that English is not only a language course but also the one in which learners can understand different types of culture and content areas.

Therefore, a model was constructed based on the above discussion, as can be seen in Figure 5, in order to show Chinese researchers a path for their future CLIL studies. Centred around multilingual and educationally diverse contexts, the CLIL research agenda in China should be expanded by researchers with an endeavour to include various aspects of evidence in their own 
studies, including performance evidence, affective evidence, process evidence and materials and task evidence. These four types of evidence constitute the backbone of empirical CLIL studies and interweave with each other, the combination of which can present the academia with a well-round, reliable and vivid picture of CLIL in practice. With respect to the relationship of these types of evidence, it may be hard to examine each of them in a truly separate way. My personal research experience informs that it could be possible to combine some of the affective evidence about stakeholders' perceptions on CLIL in the form of qualitative data with process evidence and even materials and task evidence. That is to say, it is encouraged to mix them up to triangulate the data in qualitative research in the manner that the learning process, activities and materials could be further explained and understood from the stakeholders' perspectives. Thus, the research reliability could be maximised. There could also be another case in which process evidence is merged with task evidence or sometimes materials evidence, as any learning process cannot be isolated from the design and utilisation of various materials and activities (Bušljeta, 2013). My personal suggestion, though somewhat biased, is in line with Muxi's (2018), which is to leave out materials evidence as a part of document analysis and focus on process and task evidence as a whole.

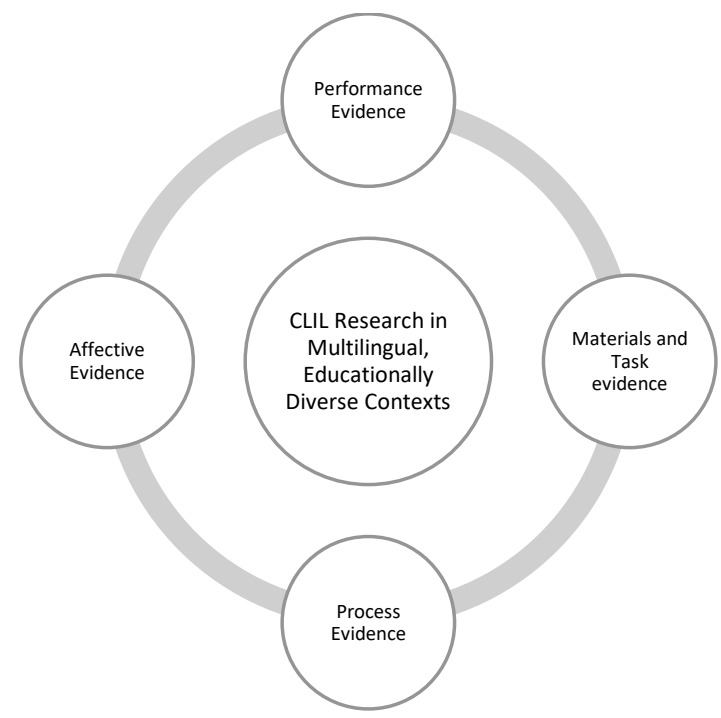

Figure 5: A Model of CLIL Research in China

Sometimes, it can be highly challenging to cover all the aspects of evidence in a paper of only a few pages. This is particularly the case in journal articles or other similar types of publications which normally require tremendously succinct writing and concise and pointed foci. I have had the same issue in my recent research, in which I collected as much evidence as possible but could not include all into a single manuscript. For example, in my latest case study of the application of CLIL into online English education amid COVID-19 pandemic, I adopted mixed-methods designs to explore the effects of CLIL on language learning and content learning proficiency of the learners who had rather differing academic levels and to understand how learning occurred in the specific context involving different learning activities and materials ( $\mathrm{Hu}, 2021)$. The presented study cannot be considered to be a comprehensive one, as affective evidence as an important indicator of the efficiency of CLIL and online learning was missed, though the data had been collected. However, a continuous effort should be made. This is how I did - opening a new Word document and starting a new manuscript to focus on something else that I had learned from the same study. Liu (2019) mentions that most Chinese researchers have been trying to 'touch' CLIL and 'go' without making any continuous effort to deepen their understanding in any further research. Continual work and research are needed. Sometimes, a longitudinal one is highly expected. This is an important point to be remembered by researchers, though I did not include it in the aforementioned research model.

At the end of this section, I would like to share how I attempted to apply the aforementioned model and the research agenda recorded in Table 3 in my own research. At the risk of sounding 'preachy', I hope this biased example could shed some light on the classic research agenda proposed over a decade ago but has been hardly employed. My research was positioned within the border of CET in a particular Chinese university that was famous for its CLIL programme combining College English with law. By adopting mixed-methods designs, I aimed at exploring the effectiveness of CLIL on the participants' language proficiency and content learning efficiency, which were measured respectively by the national standardised College English test, which was College English Test Band-6, and teacher-made assessment tasks. Affective evidence was collected by questionnaires to measure learners' motivation for language learning and foreign language anxiety. From a qualitative perspective, classroom observation, interviews and document analysis were done aimed at understanding learners' perceptions on CLIL and using their perceptions 
to triangulate what I had seen from the learning context. What was key to this research was that I used a non-randomised control group study design in the quantitative part and held a comparative view to the qualitative study. This has allowed me to gain a more profound understanding of how CLIL has been applied in this higher education provider and why CLIL is considered a better approach than traditional CET methods. Unfortunately, I excluded the teachers from my research participants due to the heavy workload I had. However, I think this research is at least an attempt, comprehensive but small, to make for a more wellround and richer CLIL research agenda in China.

\section{Conclusion}

CLIL is not a young field of discipline but is still much alive and energetic as an innovative and practical pedagogical approach, the potential of which awaits to be unlocked in China with a more sophisticated understanding to be gained from future research. The immense interest in CLIL, either in research or in education, has gathered irresistible and irreversible momentum, just like "an unstoppable train which has already left the station" (Macaro, 2019, p. 232) and is about to embark on a new expedition. However, the exploration for CLIL in China depends on the effort to be made by fervent researchers and scholars whose pivotal duty is to expand the scope of CLIL research agenda by promoting an academic milieu characterised by evidencebased practice.

With a small and somewhat repetitive attempt, I have proposed a model of CLIL research in this paper, which hopefully can provide Chinese researchers with some illuminating insight as to their future research on the domestic exploration of CLIL. A large part of this model has been drawn from Coyle et al.'s (2010) proposal that CLIL researchers are advised to present a comprehensive picture of CLIL in practice and focus on a wide range of evidence, namely performance evidence, affective evidence, process evidence and materials and task evidence. This is a classic and constructive scheme which is somehow taken lightly in western academia after the craze of CLIL research, but I hope it will be backed up and carried out in Chinese academia in a multilingual, educationally diverse context.

Of course, the research issues concerning CLIL are more than what has been mentioned roughly in this text, and there are numerous questions, which to a large are golden questions, to be answered in specific social and educational climate. However, at the current stage, the priority for Chinese researchers is to start to explore the vast ocean of CLIL, simply because the ship has sailed, and the bell cannot be unrung.

\section{Notes:}

1. Language teaching is not only about language teaching itself but also about education in a general manner. This makes the research on language teaching a complicated issue involving the examination of various concepts, such as effective learning, affective learning, inclusive learning, cognitive learning, etc. This requires the construction of a macro-picture of networks and collaboration in research groups across all academic disciplines in the long way ahead.

2. It is assumed that the research interest in elite or selective CLIL is not as essential as before in the booming era of pertinent studies (Pérez Cañado, 2020), while I hold a slightly different view that research on elite CLIL can help us explore more in the field of inclusive education, at least in China where the potential of CLIL has not been explored much yet in practice. In my recent research study, I attempted to dispel the myth of CLIL elitism in an ELE programme organised by a Chinese higher education provider amid COVID-19 pandemic ( $\mathrm{Hu}, 2021)$. The research findings are inspiring and meaningful under the current circumstance that educational inclusion has been severely affected by a sense of elitism with the growth of COVID-19 pandemic. If elite CLIL is still a valuable topic to be researched may need to be re-examined now, during such a special and lasting period of time.

Funding: This research received no external funding.

Conflicts of Interest: The author declares no conflict of interest. 


\section{References}

[1] Ahmed, F., Ami, S., \& Shah, R. A. (2019). Exploring Variation in Summative Assessment: Language Teachers' Knowledge of Students' Formative Assessment and Its Effect on their Summative Assessment. Bulletin of Education and Research, 41(2), 109-119. https://files.eric.ed.gov/fulltext/EJ1229441.pdf

[2] Alba, J. O. (2009). Themes and Vocabulary in CLIL and non-CLIL. In Y. R. de Zarobe \& R. M. J. Catalán (eds.), Content and Language Integrated Learning: Evidence from Research in Europe (pp. 130-156). Multilingual Matters.

[3] Ary, D., Jacobs, L. C., \& Sorensen, C. K. (2010). Introduction to Research in Education (8 ${ }^{\text {th }}$ ed.). Wadswroth.

[4] Baker, C., \& Wright, W. E. (2017). Foundations of bilingual education and bilingualism (6 $6^{\text {th }}$ ed.). Multilingual Matters.

[5] Brown, H., \& Bradford, A. (2017). EMI, CLIL, \& CBI: Differing approaches and goals. In P. Clements, A. Krause, \& H. Brown (eds.), Transformation in language education (pp. 328-334). JALT.

[6] Bruton, A. (2019). Questions about CLIL which are unfortunately still not outdated: A reply to Pérez-Cañado. Applied Linguistics Review, 10(4), 591-602. https://doi.org/10.1515/applirev-2017-0059

[7] Bušljeta, R. (2013). Effective Use of Teaching and Learning Resources. Czech-Polish Historical and Pedagogical Journal, 5(2), 55-69. https://doi.org/10.2478/cphpj-2013-0014

[8] Cenoz, J. (2015). Content-based instruction and content and language integrated learning: the same or different? Language, Culture and Curriculum, 28(1), 8-24. https://doi.org/10.1080/07908318.2014.1000922

[9] Chang, Y., \& Zhao, Y. (2020). The Proposal, Connotation and Significance of the Concept of Content-Language Integration (CLI)- From content-based instruction to content-language integration education. Foreign Language Education, 41(5), 49-54. http://www.cnki.com.cn/Article/CJFDTotal-TEAC202005010.htm

[10] Chionis, M., Dertili, D., Kynigou, I., \& Xanthakou, E. (2017). Implementing CLIL in a Greek Secondary School Setting: A Suggestion for Good Teaching Practices. Research Papers in Language Teaching and Learning, 8(1), 63-76. http://rpltl.eap.gr/images/2017/08-02-063-Chionis.pdf

[11] Chostelidou, D., \& Griva, E. (2014). Measuring the effect of implementing CLIL in higher education: An experimental research project. Procedia - Social and Behavioral Sciences, 116, 2169-2174. https://doi.org/10.1016/j.sbspro.2014.01.538

[12] College Foreign Language Teaching Steering Committee of the Ministry of Education. (2020). Guidelines for College English Teaching. College Foreign Language Teaching Steering Committee of the Ministry of Education.

[13] Coyle, D. (1999): Supporting Students in Content and Language Integrated Contexts: Planning for Effective Classrooms. In J. Masih (ed.), Learning through a Foreign Language - Models, Methods and Outcomes (pp. 46-62). Centre for Information on Language Teaching and Research (CILT).

[14] Coyle, D. (2007). Content and language integrated learning: Towards a connected research agenda for CLIL pedagogies. International Journal of Bilingual Education and Bilingualism, 10(5), 543-562. https://doi.org/10.2167/beb459.0

[15] Coyle, D., Hood, P., \& Marsh, D. (2010). CLIL: Content and Language Integrated Learning. Cambridge University Press.

[16] Dalton-Puffer, C., \& Smit, U. (2013). Content and language integrated learning: A research agenda. Language Teaching, 46(04), 545-559. https://doi.org/10.1017/S0261444813000256

[17] Dearden, J., \& Ernesto M. (2016). Higher education teachers' attitudes towards English medium instruction: A three-country comparison. Studies in Second Language Learning and Teaching, 6(3), 455-486. https://doi.org/10.14746/ssllt.2016.6.3.5

[18] Deng, W. (2004). Reflection on China's foreign language education planning. Journal of Chengdu University of Information Technology, 19(3), 469-471. https://doi.org/10.3969/j.issn.1671-1742.2004.03.035

[19] Hafsa, N. E. (2019). Mixed Methods Research: An Overview for Beginner Researchers. Journal of Literature, Languages and Linguistics, 58, 4549. https://doi.org/10.7176/JLLL/58-05

[20] Hanesová, D. (2015). History of CLIL. In Constantine the Philosopher University in Nitra (ed.), CLIL in Foreign Language Education: e-textbook for foreign language teachers (pp. 7-16). Constantine the Philosopher University in Nitra.

[21] Hu, H. (2021). Dispelling the Myth of Elitism and Establishing the Evidence of Inclusion: A Case of CLIL in Online English Education Amid COVID-19 Pandemic. Unpublished Manuscript.

[22] Huang, S., Xie, Y., Deng, H., Pang, R., \& Lin, J. (2019). Research on the Development of Minor Language Education in Colleges and Universities under the Background of "One Belt One Road". Knowledge Economy, (10), 107-108. https://doi.org/CNKI:SUN:ZZJJ.0.2019-10068

[23] Iskos, E., Ralls, C., \& Gegkiou, S. (2017). The Many Shades of CLIL: A Case Study of CLIL Application by English Teachers of Very Young Learners at a Greek Private School. Research Papers in Language Teaching and Learning, 8(1), 125-136. https://rpltl.eap.gr/images/2017/0801-125-Iskos-etal.pdf

[24] Kováčiková, E. (2020). English for Specific Purposes in Higher Education through Content and Language Integrated Learning. Cambridge Scholars Publishing.

[25] Liu, H. (2014). On the basic teaching methods for the lower grades of small languages in colleges and universities. Time Education, (19), 142. https://doi.org/10.3969/j.issn.1672-8181.2014.19.105

[26] Liu, D., \& Wu, Z. (2015). English language education in China: Past and Present. The People's Education Press.

[27] Liu, Y. (2019). Current status, hotspots and trends of CLIL teaching research in the past ten years-visual analysis based on CiteSpace. Journal of Taiyuan Urban Vocational College, 1, 120-122. https://doi.org/CNKI:SUN:CSZY.0.2019-01-046

[28] Llinares, A. (2015). Integration in CLIL: a proposal to inform research and successful pedagogy. Language Culture and Curriculum, 28(1), 5873. https://doi.org/10.1080/07908318.2014.1000925 
[29] Luo, Q. (2006). CLIL and Its Implications for China's EFL Teaching. Journal of Beijing University of Aeronautics and Astronautics (Social Sciences Edition), 19(3), 70-72. https://doi.org/10.3969/j.issn.1008-2204.2006.03.017

[30] Luo, Y. (2021). A New Representation of Chinese Learners. Springer.

[31] Macaro, E. (2019). English medium instruction: Global views and countries in focus. Language Teaching 52(2), $231-232$. https://doi.org/10.1017/S0261444816000380

[32] Mari, S. M., \& Shahrokh, Z. D. (2019). A Short Introduction to Comparative Research. Allameh Tabataba'i University.

[33] Marsh, D. (2002). CLIL/EMILE - The European Dimension. University of Jyväskylä.

[34] Mehisto, P., \& Asser, H. (2007). Stakeholder perspectives: CLIL programme management in Estonia. International Journal of Bilingual Education and Bilingualism, 10(5), 683-701. https://doi.org/10.2167/beb466.0

[35] Mehisto, P., Marsh, D., \& Frigols, M. J. (2008). Uncovering CLIL: Content and Language Integrated Learning and Multilingual Education. Macmillan Education.

[36] Mi, B. (2015). New development of CLIL research. Modern Foreign Language (Bimonthly), 38(5), 715-724. https://doi.org/CNKI:SUN:XDWY.0.2015-05-014

[37] Ministry of Education of the People's Republic of China. (2019). English Teaching Reform in Primary School. Ministry of Education of the People's Republic of China.

[38] Muxí, M. C. F. (2018). Identifying Effective CLIL Teaching Practice in Higher Education: A Case Study of Integrated Practices in Pre-Service Teacher Education [Doctoral Dissertation, Universitat Ramon LLULL]. Dialnet. https://dialnet.unirioja.es/servlet/tesis?codigo=228394

[39] Pérez Cañado, M. L. (2011). CLIL research in Europe: Past, present, and future. International Journal of Bilingual Education and Bilingualism, 15(3), 1-27. https://doi.org/10.1080/13670050.2011.630064

[40] Pérez Cañado, M. L. (2018). Innovations and Challenges in CLIL Teacher Training. Theory Into Practice, 57(3), 163-165. https://doi.org/10.1080/00405841.2018.1492238

[41] Pérez Cañado, M. L. (2020). What's hot and what's not on the current CLIL research agenda: Weeding out the non- issues from the real issues. A response to Bruton (2019). Applied Linguistic Review, 1-21. https://doi.org/10.1515/applirev-2020-0033

[42] Puerto, G. D., \& Vázquez, V. P. (2014). Training primary student teachers for CLIL: innovation through collaboration. Puls, 39 , $35-57$. https://revistas.cardenalcisneros.es/index.php/PULSO/article/view/213

[43] Quartapelle, F. (2012). Assessment and Evaluation in CLIL. AECLIL- EACEA.

[44] Samper, M. C. (2015). Evaluation of the implementation of CLIL (content and language integrated learning) methodology in the didactics of the English language in preschool education course taught in the preschool education teacher undergraduate program at the University of Alicante [Doctoral dissertation, University of Alicante]. RUA. http://rua.ua.es/dspace/handle/10045/52889?locale=en

[45] Sánchez-Palacios, M. C. (2017). Combining CLIL and PBL to facilitate the learning of occupational hazards in the first year of a Higher Vocational Education and Training Bilingual Programme in Business Administration and Finance [Master's thesis, Universidad Internacional de La Rioja]. Re-UNIR. http://reunir.unir.net/handle/123456789/6130

[46] Serra, C. (2007). Assessing CLIL at Primary School: A Longitudinal Study. International Journal of Bilingual Education and Bilingualism, 10(5), 582-602. https://doi.org/10.2167/beb461.0

[47] Sheble, L., \& Wildemuth, B. (2009). Research Diaries. In B. Wildemuth (ed.), Applications of social research methods to questions in information and library science (pp. 211-221). Libraries Unlimited.

[48] Stoller, F. L. (2008). Encyclopedia of language and education. Springer

[49] Švecová, L. (2011). CLIL in Very Young Learners [Diploma Thesis, Masaryk University]. MUNI. https://is.muni.cz/th/189103/pedf_m/

[50] Thamrin, E., \& Kuntariati, U. (2015). What have the teachers learnt from CLIL. Paper presented at the Conference of Trends and Challenges toward Asian Economic Community. UNESA.

[51] Tsagkari, A. (2019). Students' Perceptions on CLIL Implementation in China, Japan and Indonesia. Bulletin of Kagoshima Junshin Junior College, 49, 31-58. https://core.ac.uk/download/pdf/230313011.pdf

[52] Unterberger, B., \& Wilhelmer, N. (2011). English-medium education in economics and business studies: Capturing the status quo at Austrian universities. International Journal of Applied Linguistics, 161, 90-110. https://doi.org/10.1075/itl.161.06unt

[53] Wang, S., Xing, J. (2021). Retrospect and Prospect of CLIL Teaching Research in China. College English Teaching and Research, (2), 90-95. https://doi.org/10.16830/j.cnki.22-1387/g4.2021.02.018

[54] Xiong, T. (2018). Recontextualizing Immersion in the Chinese Context: A Sino-Canadian Collaborative Educational Program. In H. A. Spires (ed.), Digital Transformation and Innovation in Chinese Education (pp. 177-190). IGI Global.

[55] Yang, L., \& He, Q. (2019). A review of literature of domestic CLIL research from 2010 to 2019. Overseas English, (10), 7-8. https://d.wanfangdata.com.cn/periodical/hwyy-x201910005

[56] Yang, Y. (2016). The Background and Principles of CLIL Teaching Method. Journal of Anshun University, 18(4), 61-63. https://doi.org/10.3969/j.issn.1673-9507.2016.04.019

[57] Yu, S., \& Xiang, R. (2018). Comparison between and Analysis of New Bilingual Teaching Models of North American CBI and European CLIL. English Teaching \& Research Notes, (5), 2-6. https://d.wanfangdata.com.cn/periodical/zxxyyjxyyj201805001

[58] Zhao, Y., Chang, Y., \& Liu, Z. (2020). Localization of Content and Language Integrated Instruction at the Universities in China. Foreign Languages in China, 7(5), 61-67. https://doi.org/10.13564/j.cnki.issn.1672-9382.2020.05.009

[59] Zhou, Q. (2013). Challenges and Opportunities for Minority Languages in the Social Transformation in China. Journal of Yunnan Normal University (Humanities and Social Sciences), 45(2), 1-8. https://doi.org/10.1515/9781501511837-016 